\title{
Artigo/Article
}

\section{Uso e ocupação do solo e a disseminação da hantavirose na região de São Sebastião, Distrito Federal: 2004 - 2008}

\author{
Land use and occupation and hantavirosis dissemination in the São Sebastião region, \\ Federal District: 2004 - 2008
}

\section{Janduhy Pereira dos Santos ${ }^{1}$, Ercília Torres Steinke ${ }^{1}$ e Marco Túlio Antônio García-Zapata ${ }^{2}$}

\begin{abstract}
RESUMO
Introdução: As hantaviroses apresentam distribuição mundial e constituem importante problema de saúde pública. A epidemiologia da hantavirose no Brasil mostra que vem aumentando a cada ano o número de casos que são notificados e de variantes que têm sido descobertas em diversos estados e no Distrito Federal. Neste contexto, o estudo tem como objetivo principal analisar o uso e da ocupação do solo na disseminação da hantavirose no Distrito Federal, no período de 2004 a 2008. Métodos: Para a realização desta pesquisa, foram utilizados dados epidemiológicos e do uso da terra com fins de elaborar tabelas e cartogramas para detalhar a espacialização da hantavirose no território. Resultados: Dos 40 locais prováveis de infecção (LPIs) plotados no Mapa de Cobertura e Uso da Terra, 19 (47\%) ocorreram em áreas de pastagens, 10 (25\%) em área urbana (periurbana), 6 (15\%) em áreas utilizadas para a agricultura e 5 (12\%) em espaços de cerrado. Conclusões: Sendo assim, as atividades agrícolas e a expansão urbana em direção às áreas de cerrado vêm favorecendo a disseminação da hantavirose no Distrito Federal e em especialmente em São Sebastião.
\end{abstract}

Palavras-chaves: Geografia da saúde. Hantavirose. Uso do solo.

\begin{abstract}
Introduction: Hantavirosis has worldwide distribution and is an important public health problem. The epidemiology of hantavirosis in Brazil shows that the number of cases notified and the number of variants discovered in several states and the Federal District have been increasing year by year. Within this context, the main objective of this study was to examine land use and occupation in relation to the spread of hantavirosis in the Federal District, between 2004 and 2008. Methods: To carry out this investigation, epidemiological and land use data were used to drafting tables and cartograms in order to detail the special spread of hantavirosis in this area. Results: Out of the 40 likely infection sites plotted on the coverage and land use map, 19 (47\%) were in pasture areas, 10 (25\%) in urban areas (periurban), 6 (15\%) in areas used for agriculture and $5(12 \%)$ in savanna areas. Conclusions: It can thus be seen that agricultural activities and urban expansion towards the savanna areas have favored the spread of hantavirosis in the Federal District and especially in São Sebastião.
\end{abstract}

Keywords: Geography of health. Hantavirosis. Land use.

\footnotetext{
1. Departamento de Geografia, Universidade de Brasília, Brasília, DF. 2. Instituto de Patologia Tropical e Saúde Pública, Universidade Federal de Goiás, Goiânia, GO.

Endereço para correspondência: Msc. Janduhy Pereira dos Santos. Dept ${ }^{\circ}$ Geografia/ UnB. Campus Universitário Darcy Ribeiro, ICC Norte Subsolo Módulo 23, Asa Norte, 70910-900 Brasília, DF.

Tel: $55613342-2128$

e-mail: janduhy.santos@gmail.com

Recebido para publicação em 24/05/2010

Aceito em 16/09/2010
}

\section{INTRODUÇÃO}

As hantaviroses apresentam distribuição mundial e constituem importante problema de saúde pública. Representam uma antropozoonose, que tem como reservatório, roedores silvestres da subfamília Sigmodontinae. A doença foi, pela primeira vez reconhecida pela medicina ocidental durante a Guerra da Coréia, no início dos anos 1950 e em 1993 começaram a surgir casos em diversos países da América. Nos próprios Estados Unidos, o número subiu para quase trezentos casos no final do século XX e para os epidemiologistas norte-americanos a epidemia de 1993, no quadrilátero formado pelos Estados de Utah, Novo México, Colorado e Arizona tinha ligações com as alterações do ambiente especificamente com o clima em virtude do El Ninõ que acabara de ocorrer em 1991 e 1992. Países como Brasil, Argentina, Paraguai, Panamá e Chile começaram a notificar as ocorrências de hantavirose em seus territórios ${ }^{1,2}$.

Cada hantavírus infecta um roedor específico e a denominação da variante viral deriva de acordo com o local onde foi identificada pela primeira vez. Nas Américas, as cepas Sin Nombre, Bayou, New York, Araraquara, entre outras, são as mais prevalentes. Já na Ásia e na Europa, as cepas predominantes são Hantaan, Puumala e Seoul ${ }^{2}$. Existem atualmente duas formas distintas de hantavirose, a febre hemorrágica com síndrome renal que ocorre nos continentes europeu e asiático e a síndrome pulmonar e cardiovascular que ocorre nas $\mathrm{Américas}^{3}$.

Os primeiros pacientes portadores de $\mathrm{SCPH}$ (síndrome cardiopulmonar por hantavírus) no Brasil foram diagnosticados em 1993, em Juquitiba-SP, quando três irmãos adquiriram a virose em área de desmatamento. Até dezembro de 2009, 1.238 casos foram registrados no país, sendo 60 (5\%) casos confirmados e autóctones no Distrito Federal ${ }^{4}$.

No Distrito Federal, circula o vírus Araraquara que é associado ao roedor Necromys lasiurus, roedor mais abundante nas áreas de cerrado e que 
se adaptou aos ambientes alterados antropicamente, principalmente, nas áreas onde há gramíneas introduzidas para pastoreio e, dentre elas, a Brachiaria sp que é a principal fonte de alimentação para este roedor. Sobre a dinâmica desses roedores em áreas de cerrado, registrou-se que o Necromys lasiurus foi uma das espécies capturadas em maior densidade ${ }^{5}$.

Pesquisa realizada sobre a disseminação da doença no Distrito Federal permitiu constatar que a região administrativa de São Sebastião foi a mais afetada pela hantavirose com 21 (30\%) casos de hantavirose de 2004 a 2009 registrados em todo Distrito Federal ${ }^{6}$. Além disso, é também destacada a importância de se compreender os fatores ambientais como a vegetação e o clima e os fatores antrópicos relacionados com a expansão urbana e as atividades agropastoris na dinâmica espacial do agravo.

Esse aspecto demonstra a importância de buscar uma integração interdisciplinar entre as ciências médicas e as ciências ambientais no intuito de desenvolver estudos de longo prazo, para aprofundar o conhecimento dos fatores ambientais de risco e da biologia do roedor reservatório da hantavirose ${ }^{7}$.

Neste contexto, o presente artigo tem como objetivo de analisar os impactos decorrentes do uso e da ocupação do solo na disseminação da hantavirose no Distrito Federal e na região administrativa de São Sebastião, no período de 2004 a 2008.

\section{MÉTODOS}

\section{Área de estudo}

A área em estudo fica localizada na região centro oeste do Brasil, mais precisamente no Planalto Central, que possui uma área de $5.814 \mathrm{~km}^{2}$ e limita-se ao norte pelo paralelo de $15^{\circ} 30^{\prime}$, ao sul pelo paralelo $16^{\circ} 03^{\prime} \mathrm{S}$, a leste pelo Rio Preto $\left(47^{\circ} 25^{\prime} \mathrm{W}\right)$ e a oeste pelo
Rio Descoberto (48¹2’W). Entre 1992 e 1993, foram criadas três novas regiões administrativas em 1994, outras quatro, chegando a um total de 19, conforme a Figura 1.

A região administrativa de São Sebastião possui uma área de $383,71 \mathrm{~km}^{2}$, sendo que, $379,15 \mathrm{~km}^{2}$ de área rural e somente $4,56 \mathrm{~km}^{2}$ de área urbana ${ }^{8}$. A população foi estimada em 64.322 habitantes distribuídos em 50.687 habitantes na zona urbana e 13.635 habitantes na zona rural e de acordo também com o último censo realizado, São Sebastião apresentou uma taxa de crescimento anual de 9,8\% ao ano e isso se deve a migração que ocorre não somente para São Sebastião, mas também para todo o Distrito Federal ${ }^{9}$.

A economia de São Sebastião é baseada no setor primário (atividades agropecuárias) e no setor de serviços (comércio e administração pública). As atividades agrícolas são bem diversificadas com propriedades destinadas a produção de subsistência e abastecimento local e até propriedades de destinadas ao agronegócio.

\section{Dados}

Em relação à coleta dos dados epidemiológicos da hantavirose foram utilizadas informações estatísticas (quantitativo de casos de hantavirose no Brasil e no Distrito Federal e a distribuição de casos confirmados no Distrito Federal) da Secretaria de Vigilância em Saúde do Ministério da Saúde (SVS/MS) e da Secretaria de Estado de Saúde do Distrito Federal (SES/DF).

\section{Locais prováveis de infecção}

Foram realizadas observações na região administrativa de São Sebastião onde foram visitados os lugares das zonas urbana e rural onde ocorreram mais casos de hantavirose e onde foram capturados os roedores portadores do vírus. Essa etapa tem como objetivo de coletar as informações referentes ao uso do solo em áreas com ciclo

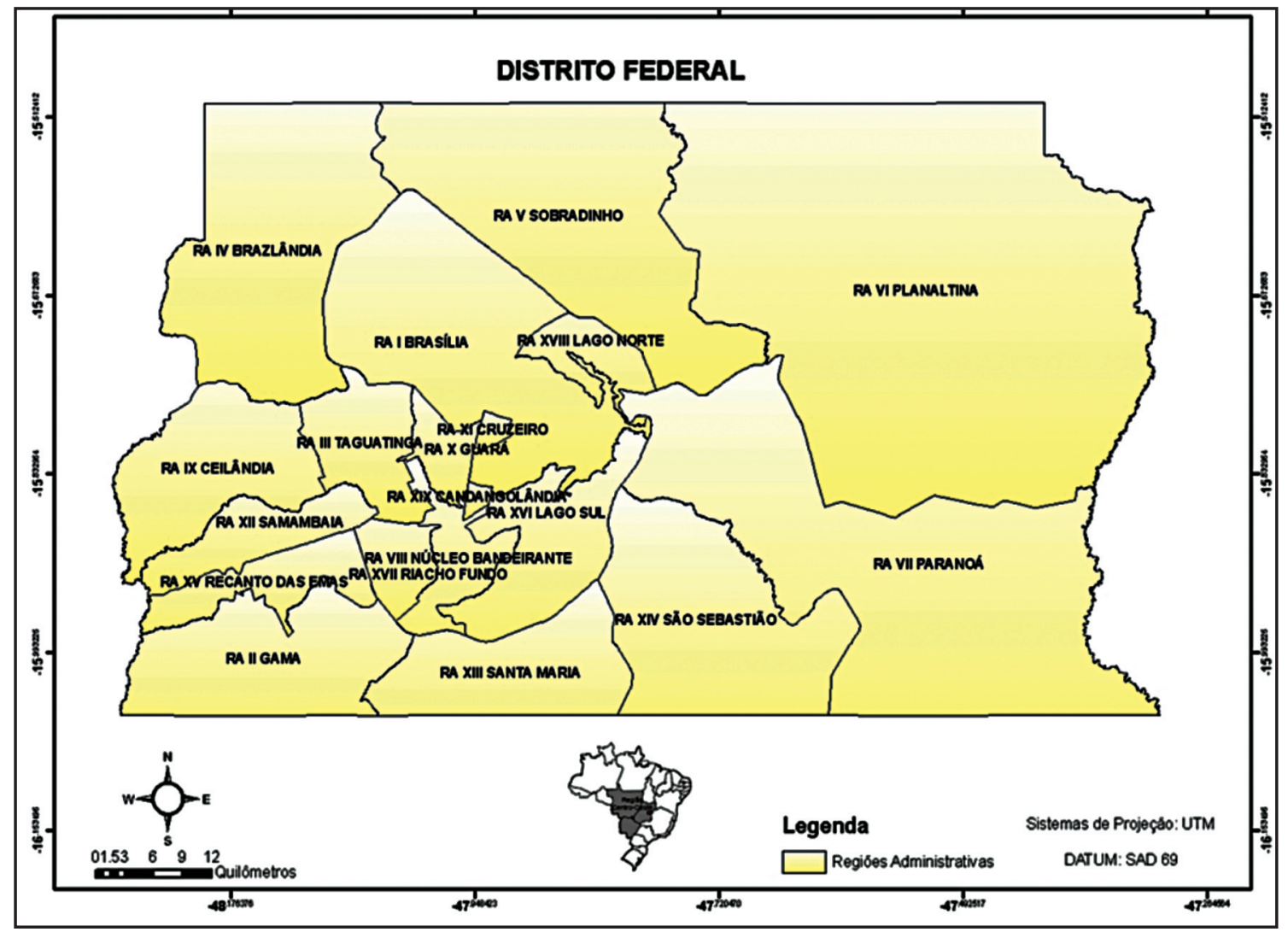

FIGURA 1 - Localização do Distrito Federal. 
de transmissão da hantavirose. Além de visitas de campo, foram obtidos dados (zona do provável local de infecção, tipo de ambiente onde provavelmente ocorreu a infecção e localização do LPI (locais prováveis de infecção) em relação à sede do município) provenientes das fichas do SINAN (Sistema Nacional de Notificações) do Ministério da Saúde. Os LPIs são definidos após a análise das fichas de notificação compulsória de pacientes que contraíram a hantavirose e de visitas as áreas suspeitas para a obtenção de coordenadas geográficas (latitude e longitude). Esses dados foram coletados na forma de sinais por um receptor GPS (Sistema de Posicionamento Global) modelo GARMIN 72 e que foram transferidos para o SIG (Sistema de Informações Geográficas) para espacialização da doença sobre o território.

\section{Mapeamento}

A próxima etapa foi composta pelo mapeamento digital da hantavirose que consistiu no cruzamento (overlay) das informações obtidas na primeira e na segunda fase do projeto. Esse mapeamento foi realizado no laboratório de geoprocessamento aplicado a saúde ambiental na Coordenação Geral de Vigilância em Saúde Ambiental (CGVAM/SVS/MS). Para a elaboração desses mapas foram usados os dados dos LPIs que foram sobrepostos nas bases cartográficas provenientes do Instituto Brasileiro de Geografia e Estatística (IBGE) e a Empresa Brasileira de Pesquisas Agropecuárias (EMBRAPA). Os resultados foram apresentados em forma de tabelas e cartogramas que possibilitaram a elaboração de uma análise crítica sobre a realidade da hantavirose no Distrito Federal.

\section{RESULTADOS}

Os primeiros casos de hantavirose foram registrados no Distrito Federal em 2004, 39 casos de hantavirose foram confirmados laboratorialmente, sendo 26 (66,6\%) residentes do DF e também com história de infecção no $\mathrm{DF}^{10}$. Os casos importados foram dos municípios do entorno que compartilham do mesmo ecossistema (cerrado) e a região administrativa que apresentou o maior número de casos foi São Sebastião com total de 14 casos $^{11}$. De 2004 até 2007, foram registrados 57 casos autóctones de hantavirose no Distrito Federal e 06 casos foram importados de outros estados (Tabela 1). No Distrito Federal, os casos estiveram distribuídos em 12 regiões administrativas (cidades- satélites) e em 5 municípios do Estado de Goiás. As regiões administrativas que tiveram casos

TABELA 1 - Número de casos e de mortalidade por hantavirose - Distrito Federal - 2001 a 2008.

Casos de hantavirose em residentes no Distrito Federal (\%) infectados em outras

UFs ou com UF de Óbitos por

\begin{tabular}{lcccc} 
Ano & autóctones & infecção ignorada & total & hantavirose \\
\hline 2001 & - & - & - & - \\
2002 & - & - & - & - \\
2003 & - & - & - & - \\
2004 & 27 & 3 & 30 & 14 \\
2005 & 15 & - & 15 & 3 \\
2006 & 6 & 2 & 8 & - \\
2007 & 7 & 1 & 8 & 1 \\
2008 & 3 & - & 3 & 1 \\
\hline Total & $\mathbf{5 7}$ & $\mathbf{6}$ & $\mathbf{6 3}$ & $\mathbf{1 9}$ \\
\hline
\end{tabular}

UF: Unidade Federadativa. notificados foram: Brazilândia, Ceilândia, Guará, Paranoá, Planaltina, Sobradinho, Recanto das Emas, Gama, Lago Norte, Lago Sul e São Sebastião. Os municípios goianos que ficam no entorno do Distrito Federal e foram afetados pela hantavirose são: Cocalzinho, Valparaíso, Santo Antônio do Descoberto, Cristalina e Luziânia.

Analisando 51 dos 57 locais prováveis de infecção dos casos autóctones de hantavirose, concluíram que, 35 (69\%) ocorreram em ambientes agrícolas (colônias e assentamentos agrícolas), 10 (20\%) em áreas de expansão/adensamento urbano, 5 (10\%) em ambientes de cerrado e somente 1 (1\%) em empreendimento de turismo rural. As alterações ambientais que vêm ocorrendo no bioma do cerrado do Distrito Federal estão favorecendo a sinantropização de roedores silvestres permitindo assim o aumento do risco de exposição ao hantavírus, pois certos roedores silvestres conseguem adentrar nas residências e viver ao redor do homem como comensais ${ }^{12}$. Com isso, esses roedores passam a serem oportunistas, como é o caso do Oligoryzomys negripes na Mata Atlântica e Calomys tener e o Necromys lasiurus (antigo Bolomys lasiurus) no cerrado brasileiro.

A região do Distrito Federal e do entorno tem demonstrado uma alta frequência de pessoas que se expõem ao hantavírus em locais abertos, pelo fato que o LPI de 59 pacientes estudados, 53 (90\%) casos estão relacionados com atividades de limpeza de terreno, práticas agrícolas (roçagem e outros), lazer, atividades domésticas (varrer o quintal, alimentar os animais, etc.) e de certos comportamentos habituais, como ficar sentado sobre o capim ${ }^{13}$. Os primeiros dias dos meses de fevereiro e de outubro marcam o início e o término do período de exposição dos pacientes ao hantavírus, com um risco acentuado de transmissão entre meados de abril e final de julho, justamente no período da estiagem, sendo assim, reforçando a necessidade de incluir estudos climatológicos na epidemiologia da hantavirose.

O mapa com as regiões administrativas (Figura 2) demonstra as áreas mais afetadas pela hantavirose desde primeira notificação do surto em 2004. Brazlândia, Paranoá, Planaltina e São Sebastião possuem juntas uma população de 319.036 habitantes. Além disso, todos esses territórios compartilham o mesmo ecossistema que é o cerrado.

Essas regiões administrativas possuem atividades agrícolas bem diversificadas como o cultivo de morangos por unidades de agricultura familiar em Brazlândia até mesmo agricultura mecanizada em larga escala desenvolvida em São Sebastião e Planaltina para a produção de grãos para exportação. Temos ainda a instalação de assentamentos agrícolas do INCRA (Instituto Nacional de Colonização e Reforma Agrária) originados de ocupações de agricultores do MST (movimento dos sem-terra).

Outra característica bastante peculiar é a expansão de áreas periurbanas em direção as áreas de mata nativa, ocasionando com isso, a perda de vegetação, pois essas áreas passam por processos de especulação imobiliária destinada a criação de condomínios para a classe média alta e de assentamentos para as classes de baixa renda. Essas áreas abrigam inúmeras nascentes de rios, por isso mesmo constitui um meio ecológico frágil, por ser de fácil erosão e contaminação pelo esgoto, resíduos sólidos e lixo e sendo assim, essas regiões administrativas apresentam ambientes favoráveis (expansão urbana, áreas agrícola, reflorestamento e outros) para os roedores que são reservatórios do hantavírus permitindo assim disseminação da hantavirose nessas áreas ${ }^{14}$. 


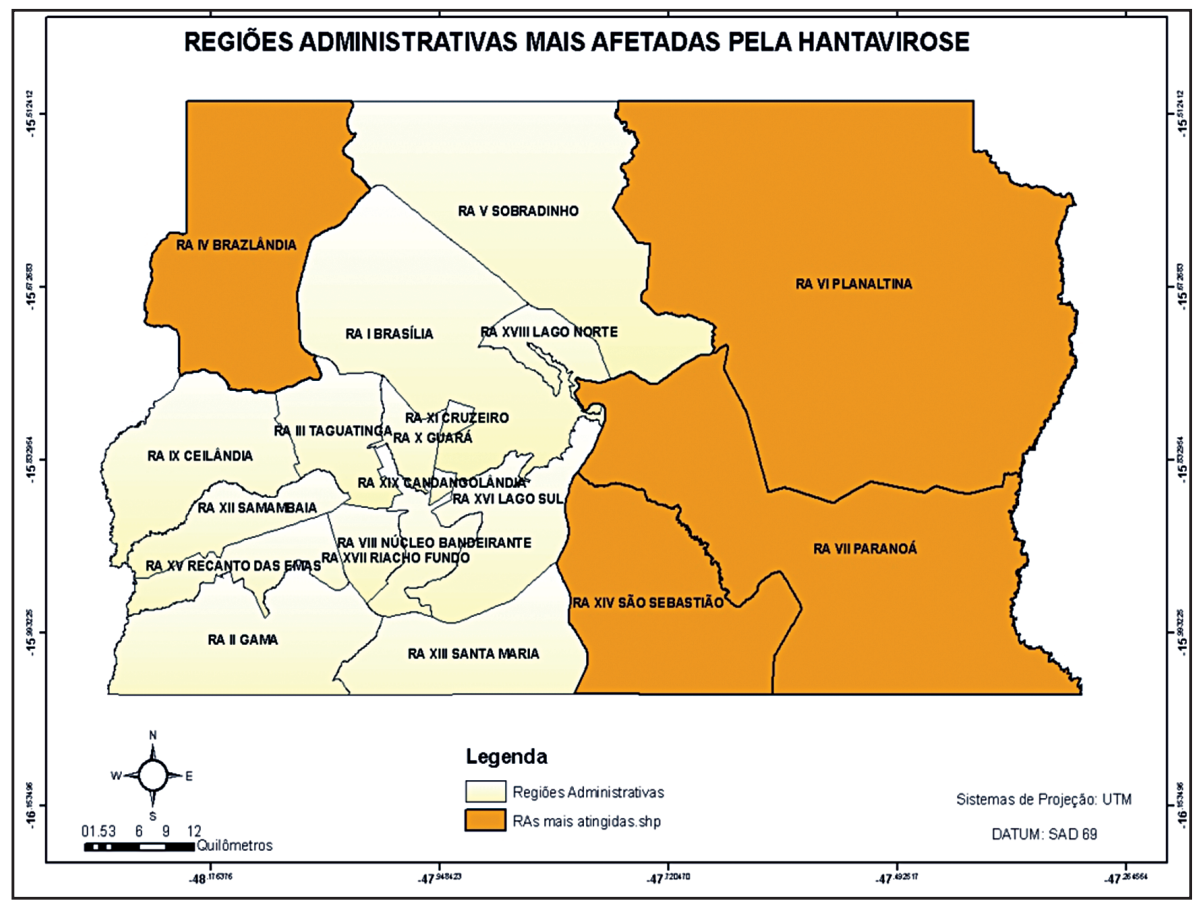

FIGURA 2 - Mapa das regiões administrativas mais afetadas pela hantavirose, 2004-2008.

Os levantamentos de uso e de cobertura da terra fornecem subsídios para as análises e avaliações dos impactos ambientais, como provenientes de desmatamentos, da perda da biodiversidade, das mudanças climáticas, das doenças infecto-contagiosas e os impactos gerados pela urbanização.

Ao retratar as formas e a dinâmica de ocupação da terra no Distrito Federal, o mapa (Figura 3) mostra os casos plotados de hantavirose de 2004 a 2008 e as caracterizações espaciais de áreas aonde ocorreram esses casos. Com a utilização de um SIG (Sistema de Informações Geográficas) foi possível determinar 5 categorias para a confecção desse mapa: água, agricultura, cerrado, áreas urbanas e pastagens. Essa classificação permitiu de maneira sistematizada o cruzamento dessas informações com a disseminação da hantavirose.

Dos 40 LPIs plotados no Mapa de Cobertura e Uso da Terra, 19 (47\%) ocorreram em áreas de pastagens, 10 (25\%) em área urbana (periurbana), 6 (15\%) em áreas utilizadas para a agricultura e 5 (12\%) em espaços de cerrado. Em relação aos LPIs, que ocorreram em área urbana, no levantamento de campo realizado percebe-se que esses casos aconteceram em áreas periurbanas próximas aos centros urbanos como o de Planaltina e São Sebastião. Outro ponto importante é que grande parte dos locais prováveis de infecção tiveram sua ocorrência em áreas com presença de pastagens.

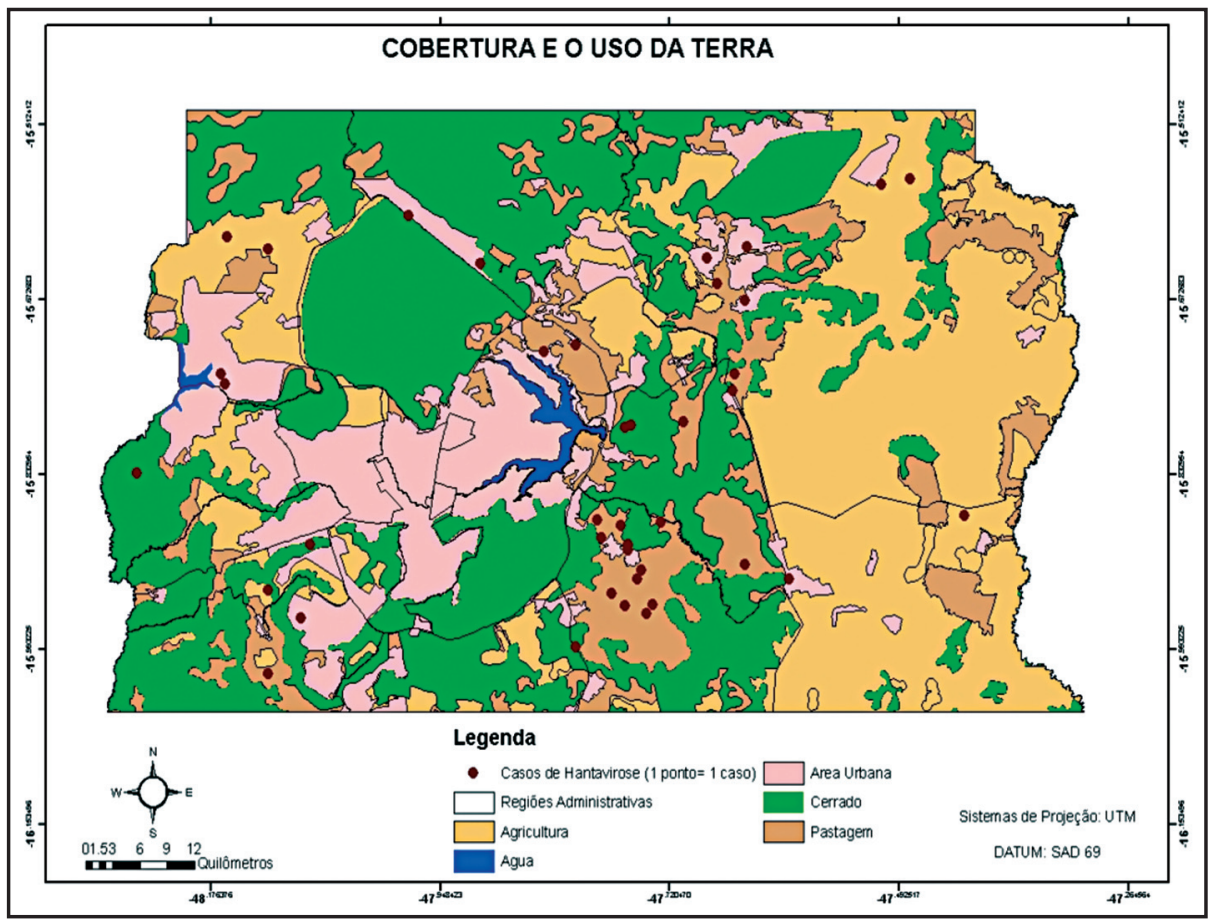

FIGURA 3 - Mapa da cobertura e uso do solo do Distrito Federal. 
É comum nas pastagens do Distrito Federal a utilização de capins do gênero Brachiaria, Brachiaria decumbens, Brachiaria humidicola, Brachiaria brizantha e Brachiaria ruziziensis. O gênero Brachiaria teve papel extremamente importante no Brasil, pois viabilizou a pecuária de corte nos solos ácidos e de baixa fertilidade, predominantes na região dos cerrados. O capim Brachiaria sp é considerado espécie exótica importado do continente africano com a intenção de suprir as necessidades agropecuárias e florestais, mas que apresentou forte impacto nas áreas rurais, muitas vezes com a eliminação de espécies nativas ${ }^{15}$.

Levantamentos de casos ocorridos em regiões de cerrados de São Paulo, Minas Gerais, Mato Grosso, Goiás e Brasília mostrou que a maioria dos casos ocorreu em habitações próximas às pastagens que utilizam capim braquiária e, em menor escala, pelas culturas do milho, da cana-de-açúcar, da soja, do arroz e do plantio para reflorestamento ${ }^{10}$.

Em épocas de estiagem, os roedores silvestres são atraídos pelas sementes do capim braquiária, pois essas sementes contêm água e que são devoradas por esses roedores para a obtenção de água nos períodos de estiagem. Nas zonas rurais do Distrito Federal, os produtores estocam seus produtos agrícolas em galpões e paióis que fazem com que os roedores sejam atraídos para se alimentarem desses grãos e muitas das vezes deixando as suas excretas contaminadas sobre esses produtos permitindo assim a contaminação por inalação ou contato com a pele.

Estes resultados sugerem que outros fatores, alheios à sazonalidade de infecção em roedores, podem estar atuando na transmissão de hantavírus no cerrado do Distrito Federal e em especialmente de São Sebastião, como por exemplo, fatores comportamentais humanos, proximidade de residências às áreas silvestres. Percebese então, que no Distrito Federal a expansão urbana decorrente da criação de condomínios ou de assentamentos para a população vem trazendo problemas não somente de ordem ambiental como a perda vegetação nativa ou comprometimento dos recursos hídricos, mas também problemas de ordem sanitária como a proliferação de vetores e de animais reservatórios de doenças infecto-contagiosas.

\section{DISCUSSÃO}

O fator uso da terra foi um importante elemento para o incremento dos casos de hantavirose no Distrito Federal e em especial na região administrativa de São Sebastião, pois alteração do ecossistema (local) em virtude de surgimento de bairros adjacentes às matas e às áreas com pastagens e, além de existir uma zona rural bastante dinâmica com propriedades que são destinadas ao cultivo de milho, cana-de-açúcar, soja, capim braquiária e capim colonião fez surgir condições propícias para o aumento da população de roedores silvestres e sinantrópicos que passaram a frequentar os domicílios e os anexos (paióis, garagens, silos, pocilgas, galinheiros e outros) e juntamente com a limpeza desses locais e por último as atividades de lazer em locais com a presença do reservatório fizeram com que a região tivesse uma taxa elevada de hantavirose.

Pereira ${ }^{16}$ reforça a importância da compreensão dos fatores ambientais ou antrópicos nos estudos sobre a dinâmica da transmissão da hantavirose. Essa importância se deve por causa das intensas alterações que vêm ocorrendo em alguns ecossistemas como o cerrado e a Mata Atlântica que são habitats do Necromys lasiurus e do Oligoryzomys negripes, roedores reservatórios dos vírus Araraquara e Juquitiba.

Vale destacar, a importância da inclusão do setor saúde no licenciamento ambiental, pois o surgimento de novas áreas habitacionais não requer somente o detalhamento dos impactos sobre o ambiente, mas, que possa fornecer subsídios em relação à presença de animais que são vetores e reservatórios de agentes patogênicos que possam oferecer para os habitantes algum risco em contrair doenças infecto-contagiosas.

Além de esclarecer junto à população sobre os impactos desses empreendimentos é necessário também a promoção de atividades de educação ambiental formal e não formal para que os habitantes possam se conscientizar a respeito de suas ações sobre o ambiente e reivindicar forma coletiva a recuperação de áreas degradadas por esses empreendimentos e assim sendo, tanto as populações emáreas rurais como as populações em áreas periurbanas próximas as matas ficam expostas a hantavirose e dependerá de atitudes dos próprios ocupantes dessas áreas de evitarem a contaminação seguindo as diretrizes por parte dos órgãos públicos envolvidos no controle da hantavirose no Distrito Federal.

\section{CONFLITO DE INTERESSE}

Os autores declaram não haver nenhum tipo de conflito de interesse no desenvolvimento do estudo.

\section{REFERÊNCIAS}

1. Organizacion Pananamerica de La Salud. Hantaviroses. Centro de Documentação. Brasília; 1999.

2. Ujvari SC. Meio Ambiente \& Epidemias. São Paulo: Editora SENAC; 2004. p.116-120.

3. Figueiredo LTM, Campos GM, Rodrigues FB. Síndrome pulmonar e cardiovascular por Hantavirus: aspectos epidemiológicos, clínicos, do diagnóstico laboratorial e do tratamento. Rev Soc Bras Med Trop 2001; 34:13-23.

4. Ministério da Saúde. Síndrome Cardiopulmonar por Hantavírus: descrição dos casos em 2007. Brasília: Secretaria de Vigilância em Saúde; 2008.

5. Donalísio MR, Vasconcelos CH, Pereira LE, Ávila AMH, Katz G. Aspectos climáticos em áreas de transmissão de hantavirose no estado de São Paulo, Brasil. Cad Saude Publica 2008; 24:1141-1150.

6. Santos JP. Aspectos geoambientais e epidemiológicos em áreas de transmissão da Hantavirose no Distrito Federal. [dissertação de mestrado]. [Brasília] Universidade de Brasília; 2009.

7. Elkhouri, MR. Hantavírus: Aspectos Epidemiológicos e Vigilância. Secretaria de Vigilância em Saúde. Brasília; 2004.

8. Companhia de Desenvolvimento do Planalto Central. Dados estatísticos do Distrito Federal. Brasília; 2004.

9. Instituto Brasileiro de Geografia e Estatística. Censo 2000. Brasília; 2000.

10. Secretaria de Estado de Saúde. Relatório epidemiológico de agravos de notificação compulsória. Brasília; 2006.

11. Bredt A, Bofil MIR, Massunaga PNT. A dinâmica da paisagem e da hantavirose no Distrito Federal. Cuiabá: II. Workshop Nacional de Pesquisas Aplicadas em Hantavírus. Caderno de Resumos; 2008.

12. Pereira LE. Estudo ecoepidemiológico de hantavírus em roedores das regiões da Mata Atlântica e Cerrado do Brasil. [Tese Doutorado]. [São Paulo]: Coordenadoria de Controle de Doenças. Secretaria de Estado de Saúde de São Paulo. São Paulo. 2006; 165p.

13. Massunaga PNT, Bredt A, Bofil MIR. Os personagens da hantavirose na região do Distrito Federal: tempo e ação. Cuiabá: II Workshop Nacional de Pesquisas Aplicadas em Hantavírus. Caderno de Resumos; 2008

14. Penna N. Fragmentação do ambiente urbano: crises e contradições. In: Paviani A, Gouvêa LAC, editores. Brasília: controvérsias ambientais. Brasília: Editora Universidade de Brasília; 2003. p. 57-73.

15. Papini S. Vigilância em Saúde Ambiental. São Paulo: Editora Atheneu; 2009

16. Santos JP. Espaço e Doença: Análise Geográfica do Surto de Dengue em São Sebastião, Distrito Federal, 2001-2002. [Monografia Conclusão Curso de Geografia]. [Brasília]: Universidade de Brasília; 2003. 